\title{
Co-Creating the Workplace: Participatory Efforts to Enable Individual Work at the Hoffice
}

\author{
Chiara Rossitto (10) \& Airi Lampinen \\ Department of Computer and Systems Sciences (DSV), Stockholm University, Stockholm, Sweden \\ (E-mail: chiara@dsv.su.se)
}

\begin{abstract}
This paper analyzes the self-organizing network Hoffice - a merger between the words home and office - that brings together people who wish to co-create temporary workplaces. The Hoffice concept entails a co-working methodology, and a set of practices inherent in opening up one's home as a temporary, shared workplace, with the help of existing social media platforms, particularly Facebook. We discuss both the practices of co-creating temporary workplaces, particularly for workers who lack a stable office and orchestrate flexible work arrangements, and the values and rhetoric enshrined in Hoffice. We collected our research materials through interviews, participant observation, and workshops. Our findings draw attention to i) the practical arrangement of Hoffice events, ii) the participatory efforts to get individual work done, and 3) the co-creation of an alternative social model that encourages trust, self-actualization, and openness. To conclude, we discuss how Hoffice is already making change for its members, and how this is indicative of a politics of care. We contribute to research on computersupported collaborative work ( $\mathrm{CSCW}$ ) by highlighting grassroots efforts to create alternative ways of organizing nomadic work and navigating non-traditional employment arrangements.
\end{abstract}

Keywords: Ethnography, Workplace, Mobile work, Flexibility, Network hospitality; politics of care

\section{Introduction}

Vignette. It is 9.00 AM on a Wednesday morning and I've come to [south of downtown] to work. As I look around trying to navigate the neighborhood and find the address I'm supposed to go to, I wonder how my today's workplace will look like, what my host is like, and who else will be at his apartment. This is the first time I go to a Hoffice, that is someone's home that is being used for the day as a shared office by a number of people who do not necessarily know each other. As I get closer to the apartment, I realize that I'm experiencing mixed feelings. I'm excited about gaining a first-hand experience of this co-working practice, I'm curious about the possibly interesting new people I'll encounter today, but to be honest, I'm also a bit concerned about going to a stranger's home. I ring the bell, John opens the door and warmly welcomes me. When the other two guests arrive, they help themselves to the coffee John has made for us. I sit at the table, while Emma and Karl prefer to make themselves comfortable on the sofa: it feels like we are all ready for the working day ahead of us. 
Hoffice - a merger of the words home and office - is a self-organizing network that brings together people who wish to co-create temporary workplaces. The network members' arrangements to come together and work in a collocated fashion are coordinated with the help of existing social media platforms, particularly Facebook. The Hoffice concept relates to a specific co-working methodology (often referred to as the structure) and to the set of practices inherent in opening up one's home as a shared workplace. The co-working methodology - providing a rhythm of silent work sessions and social breaks - along with the practices, norms, and values that underlie the facilitation of Hoffice events characterize the workplaces that Hoffice participants co-create. Hoffice is an attempt to recreate a supportive social setting to make isolated professional lives more bearable, and even enjoyable. It can serve both as an alternative and a complement to "traditional" workplaces and office arrangements, as well as to the home offices of remote workers.

We examine the socio-technical practices that constitute - but also stem from Hoffice as an emerging phenomenon, as well as the values and rhetoric enshrined in it. This contributes to research on Computer-Supported Cooperative Work (CSCW) by highlighting grassroots efforts to create alternative ways of organizing nomadic work and navigating non-traditional employment arrangements. Our analysis of Hoffice reveals both visions about desirable conditions for work, and the challenges of maintaining such initiatives without sustained structural or organizational support. This resonates with calls to reinvigorate $\mathrm{CSCW}$ research with a practice-oriented agenda (Bjørn et al. 2016) and closer engagement with contemporary theoretical developments within the social sciences (Ackerman and Kaziunas 2017), particularly by drawing attention to the situated experience of the underlying politics and issues an enterprise like Hoffice seeks to address.

$\mathrm{CSCW}$ research has had a long-term commitment to investigating workplaces and their technological development through the inclusion of workers' concerns and points of view (e.g. Hughes et al. 1992; Luff et al. 2000; Normark and Randall 2005; Suchman 1995; Schmidt 2000; Bossen and Foss 2016). However, as recently noted (Holten Møller et al. 2017), scholarship needs to revisit this commitment in a changing world of work. CSCW research has a history of contending with the problems of managerial structures and the digitalization of the workplace. For instance, in his analysis of early group calendar systems, Grudin (1988) illustrated the tensions that might emerge from the different interests that managers and other workers might have about new technologies (Grudin's paradox). Nevertheless, shifting the focus towards a grassroots initiative, like Hoffice, opens up a new set of issues related to workplaces where work relations and the enterprise of work are guided by values such as trust, support and mutual care, rather than being organized under narratives of production. The lack of a managerial and hierarchical organization of work that is characteristic of Hoffice foregrounds an analytical focus on how people make change for themselves and others. This is in contrast with the traditional focus on how work unfolds within a more consolidated network of obligations and interdependencies. 
By discussing Hoffice, we illustrate how narratives of "flexible" forms of knowledge work (Barley and Kunda 2006; Bourne and Forman 2013; de Carvalho et al. 2017; Gregg 2013; Liegl 2014; Gray et al. 2017), detached from the here and now of office spaces, call for taking on a broader - and partially different - set of research issues. While flexible work arrangements (e.g. "work from home" policies) and short-term employments (e.g. freelance work and independent contracting) have become a common reality in the global job market (Gregg 2013; Gray et al. 2017), many of the associated challenges have received little attention within CSCW. Hoffice is significant, in this respect, as it provides a novel example of sociotechnical infrastructure that enables participatory and collective efforts to carry out flexible and individual forms of work. The set of socio-cultural values and norms inherent in the Hoffice concept, together with the practical and procedural enactments that make it happen, provide CSCW with a vision of a workplace that does not focus on the efficiency of collaborative work per se, but rather on well-being, selfcare and care for other people. Hoffice depicts an alternative social model for a workplace where trust and openness towards others are paramount, instead of profit, competition, or managerial structures. This is achieved through transforming the purported home office into a self-organized co-working space that comes about when individuals (hosts) decide to share it with other people (guests), including acquaintances, or even strangers. In this respect Hoffice presents similarities with network hospitality arrangements where technology facilitates encounters in domestic spaces (e.g. Bialski 2012; Lampinen 2016; Molz 2012).

Computers fade into the background in everyday accounts of Hoffice events. The circulation of working resources, and other issues concerning the mobilization of work (Perry et al. 2001; Brown and O'Hara 2003; Luff and Heath 1998; Rossitto and Severinson Eklundh 2007 and Rossitto et al. 2014; Su and Mark 2008) appear easily manageable within this setting. In Hoffice, the role of technology, especially social media platforms, is primarily central to creating favorable conditions for people to come together in a co-located manner, and to co-work according to a shared rhythm.

Through an ethnographic study, conducted over a period of 16 months, we have gained an understanding of the reasons for organizing Hoffice events and attending them, as well as of how the resulting practices can be interpreted as a sustainable alternative to contemporary forms of flexible work. In presenting our analysis, we, first, describe the practical arrangements of Hoffice days (e.g. how the work structure is applied, the technology involved, and how physical places are used). We, then, discuss the nature of participatory efforts that enable individual work, and illustrate how the experience of partaking in Hoffice contributes to an alternative social model that encourages trust, self-actualization, and openness towards others.

How can CSCW research benefit from analyzing Hoffice? Our investigation illustrates how Hoffice is already making change for its participants. Partaking marks a shift from the individual (Barley and Kunda 2006; Gregg 2013; Nippert-Eng 1995) to participatory efforts to co-create an effective and supportive context to orchestrate flexible work arrangements. Hoffice envisions a way to act collectively and to come 
together by focusing on the quality and meanings of interactions between people, rather than merely on technological design. As care for oneself (e.g. selfactualization and well-being) and for others (e.g. togetherness, reciprocal support, trust, and mutuality) is central to its situated practices, Hoffice offers a model for exploring a vision of the workplace based on politics of care (Light and Akama 2014, 2017), rather than merely on values such as connectivity, profit, productivity, and efficiency. Ultimately, this paper speaks to how CSCW might conceive of its role in co-creating more desirable conditions for work, balancing critique of precarious work conditions with pragmatic approaches to action (as suggested by Holten Møller et al. 2017).

\section{Background}

We draw on two broad lines of prior work to contextualize our study. Firstly, considering research on nomadic work practices and flexible work arrangements positions Hoffice as a new chapter in a well-established body of literature on the changing workplace, as well as on work practices on the move, rather than stably situated in familiar office arrangements. Secondly, research on the sharing economy, and practices of network hospitality in particular, illustrates that Hoffice is not without precedent in that face-to-face encounters in domestic spaces have been facilitated with the help of online systems for well over a decade.

\subsection{Nomadic Work Practices and Critical Perspectives on Working "Anytime", "Anywhere"}

The promise of providing connectivity anytime anywhere, through the development of mobile devices and services (Kleinrock 1995, 1996), introduced the vision of the nomadic knowledge worker as a professional who is enabled to work anytime and independently of physical locations. Critiquing this naïve, technology-centered approach to mobile work was at the core of early $\mathrm{CSCW}$ investigations of nomadic work practices.

Research on nomadicity and collaboration focused, for instance, on the variety of technology-mediated practices that workers enact in order to mobilize their work (Wailenmann 2003; Su and Mark 2008; Perry et al. 2001; Luff and Heath 1998). Investigations drew attention to the situated nature of nomadic practices, and to how place and work mutually shape each other as people move work across locations (Brown and O'Hara 2003; Rossitto and Severinson Eklundh 2007; de Carvalho 2014). These studies (Rossitto et al. 2017) emphasized the practical achievements involved in making it possible to work at several places by drawing attention to issues such as: i) place-making (Brown and O'Hara 2003; Perry et al. 2001; Rossitto and Severinson Eklundh 2007; Rossitto et al. 2014), that is the range of practices enacted to create the conditions to work, including micro-mobility and the mobility of artefacts (Luff and Heath 1998); ii) planful opportunism (Perry et al. 2001), that is the planning undertaken 
to make sure that working resources are available while on the move; iii) technological discontinuities (Bogdan et al. 2006), that is the changes occurring in the technologies used as collaborative practices are moved across locations; iv) the negotiation of the constellations of technologies to be used (Rossitto et al. 2014) as an essential aspect of nomadic practices in collaborative work; and v) the infrastructure of nomadic work ( $\mathrm{Su}$ and Mark 2008), that is, the range of situated practices to recreate the mobile office. This included, for instance, efforts to assemble human and non-human actants, to seek resources, and to remain connected to the main office.

Over the years, mobile computing has developed at a fast pace, and working "anytime, anywhere" (Kleinrock 1996) has become an everyday practice for many workers in western countries, rather than merely a computational vision. The broad variety of mobile apps and devices, along with the pervasiveness of cloud services has normalized the nomadic practices encompassed in moving resources across locations. While we do not argue that the challenges of mobile work have been "solved" in any comprehensive way, the case of Hoffice suggests that they have become easily manageable for some groups of knowledge workers. This point is corroborated by accounts of freelancers working regularly at coffee shops (Liegl 2014), as well as by the growing number of dedicated co-working places (e.g. McLaren and Agyeman 2015), such as office hotels and airport lounges.

Issues of how technology-mediated nomadicity (de Carvalho et al. 2017) and always-on connectivity shape the desired boundaries between work and personal life have so far been left with lesser attention within CSCW. Glamorous narratives of being able to work anywhere (Czarniawska 2014), often associated with promises of individual empowerment and flexibility are now increasingly questioned (Gray et al. 2017). Recent investigations have illustrated how current politics around flexible work arrangements (e.g. freelance work, independent contracting, and working from home policies) may nurture a tendency to put work at the center, sometimes at the expense of other types of personal fulfilment (Bourne and Forman 2013; Gregg 2013). Relatedly, Barley and Kunda (2006) have examined various forms of flexible work, illustrating that its reality often differs substantially from its promise. In their ethnographic account of modern knowledge economy, Barley and Kunda show, for instance, how contractors are often left alone in promoting their careers, managing their "market value", and strategizing about how to allocate time, upgrade their skills, and maintain essential contacts.

The widespread adoption of mobile technologies that allow people to access work beyond traditional physical constraints has taken place in sync with restructuring and streamlining knowledge work processes so as to increase efficiency and maximize profits (e.g. Gray et al. 2017; James 2014). Workers are often offered the possibility to work full-time from home (Gregg 2013), but flexibility is not equally desirable for all, and may be an unwanted burden for some. For instance, a recent experimental study in the field of economics (Mas and Pallais 2016) illustrates that workers vary in how much they value different forms of worker-driven flexibility (that is, arrangements that increase their freedom to organize their work in a way that suits them) but 
uniformly detest flexibility in the form of employer discretion (such as zero-hour contracts or being on call).

In this paper, we build on this body of work to discuss Hoffice as an example of a self-organized, temporary workplace conceived as an answer to the challenges of self-employment and flexible work (e.g. the solitude and the difficulty of managing work that may come with working from home). We will illustrate Hoffice as an attempt to co-create an alternative workplace that nurtures self-actualization and the social dimension of work for individuals who, similarly to the nomadic workers studied in prior research, can work at several locations or have made the choice to forego a regular job in a traditional work organization.

\subsection{Network Hospitality and Care in the Sharing Economy}

Whenever we have discussed this study, or even just described the idea of Hoffice, we have often encountered disbelief that something like the Hoffice network exists and manages to attract participation. Given these reactions, it is worth noting that Hoffice is not without precedent. Over the past decade, social scientists in hospitality and mobility studies, most importantly Molz (2012) and Bialski (2012), have examined the emergence and increasing popularity of systems that encourage the arrangement of face-to-face encounters in domestic spaces. Germann Molz (2014) refers to the kind of sociality that emerges around these mobile, peer-to-peer, and online-to-off-line social networks as network hospitality. While network hospitality itself is a relatively new phenomenon, Molz (2012) rightfully points out that, in a more general sense, practices of hosting, guesting, and extending hospitality to strangers have, of course, a much longer history, for instance, in pre-Internet efforts to arrange homestays around the world with the help of telephone calls, letters, and postcards (Molz 2012).

The two most common examples of network hospitality in prior literature within HCI have been Couchsurfing and Airbnb. As summarized in Lampinen and Brown (2017), Couchsurfing and Airbnb both facilitate connections between guests and hosts who are willing to make private spaces available, with the key distinction that Airbnb supports a well-defined (and often less personable) monetary exchange, while Couchsurfing hosts offer guests a place to stay with the expectation of generalized reciprocity. In so far as hosting takes place in the hosts' primary home, questions of social and spatial boundaries are at stake, and (re)configurations of these boundaries between shared and private spaces vary depending mostly on the hosts' preferences (Lampinen 2016). For instance, most of the Couchsurfing hosts that Lampinen (2016) interviewed saw no reason for their guests to enter some areas in their homes (e.g. the host's bedroom), but they were willing to allow guests to use such spaces if there was a need to do so - for example in order to make a private phone call. These boundary rules can be communicated in online profiles as well as voiced in instant messages and in-person conversations between hosts and guests (e.g. Lampinen 2014; Lampinen 2016). However, it seems common for network 
hospitality to rely somewhat on the courtesy of the guests and on shared understandings of how one should behave when visiting a home as a guest, rather than explicit rules.

Expectations of intense, sociable encounters have been noted as characteristic of network hospitality especially in the case of Couchsurfing (e.g., Bialski 2012; Germann Molz 2014). Further work has highlighted the importance of trust in motivating both hosts and guests to participate in this activity that involves both risk and uncertainty (Parigi and State 2014; Lauterbach et al. 2009; Rosen et al. 2011; Tan 2010). These two social dynamics are relevant in the context of Hoffice, too. Nevertheless, the sense of vulnerability and the importance placed on interacting with likeminded people are likely to be less pronounced when getting together for a day of work at Hoffice, than when sleeping the night in the hosts' home like in the case of leisurely or touristic Couchsurfing encounters.

Another parallel to be highlighted between Hoffice and network hospitality, as practiced via Couchsurfing and Airbnb, are the social dynamics within households. The presence and the preferences of family members or housemates may complicate individuals' participation in both settings. Bialski (2012) and Buchberger (2012) where among the first to emphasize that while it is easy to focus on host-guest relationships, network hospitality does not necessarily take place between one host and one guest. When it comes to negotiations regarding network hospitality via Couchsurfing, Lampinen (2016) has documented that where household members' preferences are mismatched, prioritizing consensus within the household over participation may mean that the idea of hosting is abandoned, if not everyone wants to welcome particular guests.

Finally, we see Hoffice as connected to the broad visions of the sharing economy (Schor and Fitzmaurice 2015). These visions have been heavily critiqued over the past years, but if we return to the early, community-oriented versions of what the sharing economy could encompass, then Hoffice clearly connects to narratives about sharing. With its emphasis on opening up private homes for collective use, Hoffice encourages co-creation of sociable events that seek to make use of underutilized resources while, perhaps more importantly, fostering values such as care.

\section{Studying the Local Hoffice Community}

For this study, we set out to create a grounded understanding of how the local Hoffice community functions and how Hoffice workdays are arranged and attended in practice: How do people agree and coordinate where, when, and with whom coworking takes place? What is the role of the Hoffice work structure and how do attendees experience its proposed rhythm of silent work sessions and social breaks? Moreover, we wanted to understand why people are attracted to the community, what makes participation worthwhile and, equally importantly, what might hinder getting involved, or lead to lessening one's involvement. To address these questions, we conducted fieldwork in the Hoffice community in Stockholm, Sweden, from 
June 2016 to October 2017. We collected data through interviews, participant observation, and workshops. In what follows, we introduce Hoffice, describe our fieldwork and analysis procedures, and reflect on positionality.

\subsection{The Hoffice Network}

The Hoffice network was founded in Stockholm, Sweden, in the beginning of 2014, with the main intention to facilitate the collective use of private homes as shared offices. The $\mathrm{H}$ in Hoffice stands for "Home". The main underlying vision is to provide a framework for the creation of facilitated co-working events in private homes for freelancers, independent contractors, and other flexible workers, but also for students, retirees, job-seekers, or others who do not have (or have chosen not to have) access to formal office arrangements. Hoffice is a self-organizing network that has little formal structure in place to support its activities. It does not have or seek mechanisms to make money. The network relies on its members' joint efforts to improve their own and each other's work lives, and participation is entirely voluntarily. At the moment of writing this paper, there are 2043 members in the Hoffice Facebook group in Stockholm. Their backgrounds vary, including entrepreneurs, freelancers, students, retired people, job-seekers, and employees of companies or universities who have the possibility to work away from their regular offices. The main digital technologies used by the Hoffice network in Stockholm are Facebook and a dedicated website ${ }^{1}$. The Facebook group is mostly used to advertise and organize Hoffice events, while the website provides an overview of Hoffice in terms of the underlying ideas and proposed working practices.

\subsection{Fieldwork}

Having followed the emergence of Hoffice before beginning our study, we had a general sense of the network to guide our inquiry, but little personal experience and limited knowledge about its members' points of view. To kick off our fieldwork, we first reached out to Christoffer Gradin Franzén, one of the co-founders of the Hoffice network and a key person in the local community. We identify Gradin Franzén with his consent, since it would be very difficult to analyze and discuss his role in the community without revealing his identity. As a merger, the signifier "Hoffice" denotes two very specific concepts, home and office, that stand at the core of the network's values and what it seeks to pursue. This would make it difficult to talk about it without mentioning its real name. While we refer to all other participants in the study with pseudonyms, we resonate with conventions of social science research (see, for instance, in Lingel 2017) when revealing the name of the network and its cofounder. Regarding our case specifically, discussing a people-led initiative like

\footnotetext{
${ }^{1} \mathrm{http} / /$ hoffice.nu/en/
} 
Hoffice without identifying it would both be a failure to give credit where it is due, and an inappropriate abstraction of action that is local and specific in the pragmatic change it seeks to make.

The first author set up a formal interview with Gradin Franzén, both to establish an understanding of the founders' perspectives about the community, its practices, and challenges, but also to build rapport and facilitate access to the community. The interview tackled issues such as motivations, visions and models underlying the Hoffice network, the role of the work structure, what it takes to become a Hoffice host and/or guest, the challenges the community juggles with, the role of Facebook in managing and facilitating Hoffice events, as well as Gradin Franzén's own role within the community. The interview was conducted in English and lasted about an hour. It was audio-recorded and transcribed verbatim.

We then began studying the community through participant observation (Dewalt and Dewalt 2002) and informal interviews (Weiss 1994) with Hoffice attendees. Our observations took place both at physical Hoffice events, at a local public library, in private homes, and online where we focused on members' interactions in the local Facebook group. Eight sessions of participant observation (excluding online observation that was done on a more continuous basis) were carried out, for a total of about 50 hours. During the participant observation, we focused on aspects such as the social interactions between the attendees (both during the working sessions and the breaks), the situated practices enacted to keep the structure, the social norms emerging from being-together, and from being a guest at a stranger's home. Between 7 and 11 guests were present during the observations at the public library. A room at the library had been booked for these events. The room was large enough to accommodate about 20 people. The table arrangements varied: sometimes all the participants sat around one large table, while at other times the tables had been arranged to let groups of four to six people sit together. The room also included a sofa area where people could spend their breaks socializing with each other. One observation was carried out at a private home (located just outside Stockholm's inner city), where the first author participated as a guest. Four people, including the author, were present at the event and none of them was involved in any other data collection. This event took place in a two-room apartment, where the open-plan kitchen and living room had been set up as the shared working area. To preserve the host anonymity, we do not include any pictures of this home arrangement. (Our opportunities to conduct participant observation in homes were severely constrained by the fact that few home-based events were advertised on the Facebook group during the study period.)

The participant observation sessions were also occasions to carry out informal interviews with some of the attendees, mostly during lunch breaks. These conversations lasted between 45 and $60 \mathrm{~min}$ and they enabled us to collect data from five different persons: two were one-to-one conversations, while the last one was a discussion between the first author and three of the attendees. The discussions were mostly concerned with the overall experience of participating in the Hoffice 
community, including both practical enactments (e.g. arranging events) and aspects of the felt-like experience of participating (e.g. sense of togetherness and creativity).

During the fieldwork, we took field notes about our participation, accounting for episodes we had noticed during the day, describing our experiences and marking down analytical thoughts that could then be used to guide further inquiry. In some cases, our field notes are accounts of non-participation: events that we were planning to attend, but that got cancelled at the last minute, and others that we chose not to attend despite wanting to gain more Hoffice experience. These latter events, in particular, were useful to reflect on what kept us from going, and how that might be indicative of the types of issues that hinder participation more broadly.

Through online observations, we collected screenshots about events, and conversations that were posted on the Facebook wall of the local group. A total of 40 screenshots was collected over a period of 1 year; they were captured as they provide examples of the type of information people share when organizing events (for instance, the number of work stations available, lunch routines, etc.), the attendees' response to the creation of an event, or how members talk to each other through the Facebook group. We also collected screenshots documenting the variety of Hoffices that are organized, for example, thematic Hoffices (e.g. writing Hoffices, local neighborhood Hoffices, etc.), or Hoffices that include special activities (e.g. after work training, cooking lunch together, etc.). It should be noted that the amount of posts we deemed as relevant varied depending on the rhythm of the online activities, which was not constant throughout our data collection period.

To complement this data, we thoroughly read and documented the website that introduces the Hoffice concept and the Stockholm Network. The goal was to compare the written descriptions of how Hoffice is supposed to work, and what it is meant to be, with members' situated experience (Suchman 2007) of their actual participation.

In addition to these observations, we organized an internal Hoffice at our university department, to experiment with the applicability of the concept into a traditional work setting. This effort was inspired by our discovery that the Hoffice structure was being put to use in a variety of settings that differed from the original idea. For example, some were using the structure at their regular offices and others used it at home with a friend or a partner, without opening up the event for participation to the broader community.

Finally, we carried out two workshops. The first was organized as a group interview and it aimed at unpacking participants' situated experience of Hoffice. This workshop was an all-day event for experienced Hoffice participants. We first worked with the Hoffice structure from morning until lunch, and then ran the group discussion in the afternoon. The discussion was targeted at exploring participants' experiences of Hoffice, their thoughts about the strengths and weaknesses of the network, and their ideas about how the concept and practices could be further developed. These workshops deepened our involvement in the Hoffice community and our relationships with Gradin Franzén in particular, as we organized them in 
collaboration with him, with the dual purpose of complementing our research and exploring future possibilities for the Hoffice network in Stockholm. The invitation to this workshop was sent out by Gradin Franzén through the Facebook group, and a number of seven people agreed to participate. The authors facilitated this workshop, while Gradin Franzén decided not to attend to avoid steering the discussion. This workshop played a key role in our study as it allowed us to collect participants' accounts about Hoffice and strengthen our emerging analytical observations through discussing central ideas with the participants. The second workshop was a half-day event where different stakeholders came together to discuss how the Hoffice structure could be applied to different settings and, secondarily, what kind of technologies could facilitate the functioning of the Hoffice network better than Facebook. This latter workshop is part of our broader design efforts in researching Hoffice and the domain it illuminates. We do not use our documentation from it in this manuscript, as the design orientation is beyond the scope of this paper.

\subsection{Reflections on Positionality}

Our involvement with the project started in June 2016 when the interview with Gradin Franzén was conducted. At this stage, he was a key informant of our study and supported our research by introducing us to the everyday practices of working at Hoffice. Our relationship with him has later on reflected on our entry to the field (Fatterman 2010). For instance, our first participant observation coincided with an event that was facilitated by him, as knowing him lowered for us the threshold of taking part in Hoffice for the first time. Although actively participating in the work sessions and the collective breaks, we sought to have as little influence as possible. Our participation to the breaks, and to the other group activities, was therefore limited to following the instructions that were given by the facilitator. During the lunch breaks, attendees were keen on sharing their Hoffice experience with us. While these moments have been valuable for data collection, and while we did encourage such discussion, throughout our participation we have come to realize that sharing personal Hoffice experiences is a common topic among participants.

We surmise that our relationship with the founder has most visibly influenced our position within the network during the workshops. Since we did not personally know the people who were invited to the first workshop, it would have been more problematic for us to reach out to them and bring them together for a discussion. However, Gradin Franzén was not involved in the design of the discussion template for the workshop, neither did he participate in the workshop discussion. This, we believe, gave the participants an opportunity to speak freely about their Hoffice experience. At the same time, because of his intermediary role, the trust the participants placed in him extended to us. We deem that this was one reason for the participants' deep engagement in the workshop.

To summarize, the co-founder was initially the key informant who enabled us to gain an overview of the Hoffice Network. Throughout the study he has facilitated our 
entry to the field, particularly by welcoming us to the Hoffice events he facilitated, and by helping us to recruit participants, yet without setting up the workshop agendas.

Finally, while both authors work and live in Stockholm, where the study was conducted, we are not originally from the area, and we are not native speakers of the local language. This served to make it clear for us that, while the Hoffice network is oriented toward openness and inclusion, at the time of the study it consisted primarily of native Swedish speakers. This in itself could discourage aspiring participants who do not speak the language. For us, studying the community was a welcome challenge that drew us into social circles different from our everyday networks, and provided us with an organic setting for speaking Swedish and meeting "local" people. Part of the fieldwork (including a large part of both workshops) took place in Swedish, and the related materials were transcribed and analyzed in Swedish. Citations from the workshop discussion and interviews have been translated for this paper.

\subsection{Data Analysis}

The fieldwork process itself was already interpretive, both in terms of the field notes we wrote and shared with one another, and in terms of how our prior observations guided our choices, for instance, when it came to deciding how to structure the workshops and which themes to explore. Taken how reflective the research process had been before we began a more formal analysis of the material, we already had a set of preliminary ideas for possible central themes (i.e. the role of the structure, juggling different roles etc.). In preparing this article, the authors carried out a thematic analysis (Bryman 2012), and systematically worked through all the collected material collaboratively. We revisited and read through all notes and transcripts, marking down themes as they came up. This allowed us to pay attention to themes that we might have missed in the midst of the fieldwork, and to consider what the materials could reveal once they were analyzed as a collection. Through a collaborative and iterative process of revisiting the materials several times, we aggregated the resulting themes in three central overarching themes: 1) how Hoffice works, in terms of work structure, the technologies involved, and the physical places used, 2) the participatory efforts that are made to get individual work done, and 3) Hoffice as an alternative social model that encourages, trust, self-actualization, and openness towards acquaintances.

\section{Findings}

Our analysis elucidates strategies and situated practices enacted to create a supportive social context for enhanced individual productivity and well-being. We draw attention to three overarching themes from our analysis: 1) the practical arrangements of Hoffice events, including the adoption of the work structure, the digital technologies used, and the physical places inhabited, 2) the participatory efforts made to get 
individual work done, and 3) the co-creation of an alternative social model that is centered on values such as trust, self-actualization, and openness to new acquaintances.

\subsection{The Practical Arrangement of Hoffice Events}

Hoffice events are advertised through the Facebook group of the local Hoffice network. Adopting Facebook's terminology for activities, an event refers to a working day occurring (typically but not exclusively) at a private home (Figure 1).

Once an event is created on Facebook by a member of the network who is willing to serve as $a$ host - that is, to share one's home as a temporary workplace - other members are welcome to show their interest and sign up to attend it. When a Hoffice event takes place, guests (and the host) are free to work on anything they choose. Anyone in the network can host an event. During data collection, we encountered both first-time hosts and regular ones.

Activities undertaken during Hoffice events are not limited to paid work. For instance, during our data collection, we also met students transcribing lecture notes as well as people attending Hoffice to take care of mundane tasks like paying their bills.

\subsubsection{The Hoffice Work Structure}

A core tenet of the Hoffice community is the work structure, typically referred to by participants as "the Hoffice structure", or just "the structure". This consists of the alternation of 45-min work sessions with short breaks between them, and a longer one around lunch time. The breaks are usually taken together and involve joint activities led by whoever has an idea of what to do (often the host), with the intent to relax, socialize, and get to know other people. A regular day spans from 9.30 to 16.30 but this time is not fixed: hosts are welcome to organize events in line with their preferences, and attendees are free to arrive and leave when it best suits them. The host is usually responsible for introducing and keeping the structure of the work day. This work of guiding the group to stick to the structure is referred to as facilitating the event. This includes timing the alternation of work sessions and breaks, along with giving advice on what to do at different moments - an effort that is especially important when there are newcomers in attendance.

The work structure has the instrumental and practical goal to organize the working day into cycles during which particular tasks or activities can be accomplished. In this sense, it is similar to frameworks such as Scrum (Verheyen 2013), nowadays extensively adopted in software development. However, during Hoffice events, the synchronized alternation of working sessions and breaks is meant to support individuals in accomplishing their own, personal objectives as well as to foster a sense of mutuality and trust among the participants. This sense of support and the opportunity for building a positive and supportive group is a core characteristic of Hoffice as 


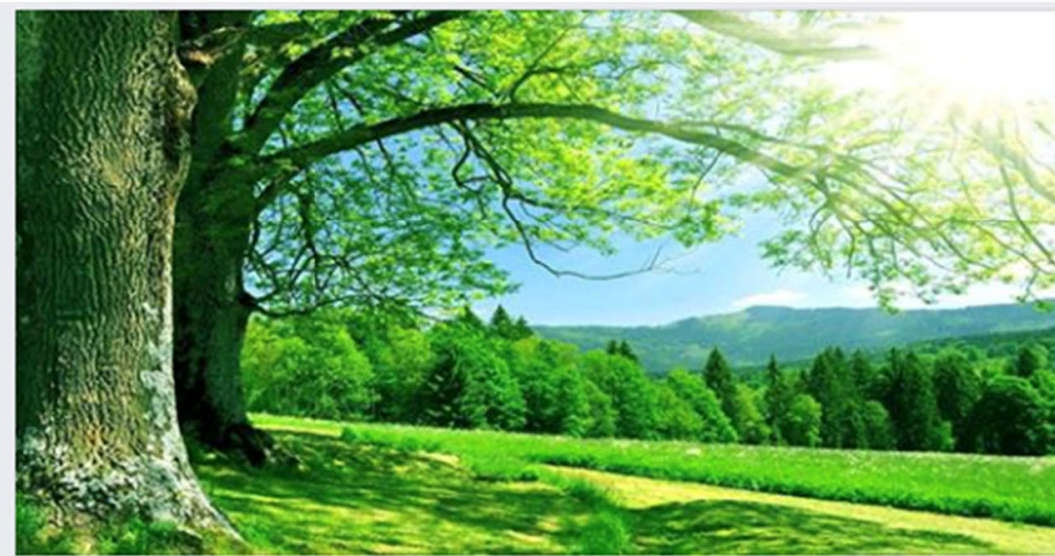

NOV

15 Event for Hoffice.nu - Stockholm · Hosted by

\section{Going}

\section{Save Invite}

(1) Tomorrow at $10 \mathrm{AM}-4 \mathrm{PM}$

Tomorrow $\cdot-1-6^{\circ}$ Partly Cloudy

- Höghuset Björkhagsplan

Stockholm, Sweden

3 Going $\cdot 0$ Maybe $\cdot 0$ Invited

Invite your friends to this event

Välkommen, ny som stammis!

Max 8 pers.

Skriv vilken tid du avser att komma.

Vegetarisk profil. Vänligen ta dina mest katthårsfria kläder ^^ .

\section{VAD FINNS HÄR?}

- Flera arbetsrum med bord, stolar, soffor, myshörnor mm

- Wi-fi

- Telefonrum / mötesrum

- Kök med spis och kastruller att använda. Ingen micro.

Konsum, Thaimat och Sushi alldeles nära.

- Magisk utsikt!

Figure 1. . An advertisement of a Hoffice event on Facebook. The advertisement contains information about the host, the number of guests who are planning to attend, the date, the venue, as well as details about the maximum number of guests, wi-fi, food arrangements, and the surrounding neighborhood 
a co-working setting, rather than cooperating on shared tasks or interdependent activities.

Another important part of Hoffice is that participants do a check-in in the beginning and in the end of each working session. This means that all attendees state their goals for the upcoming session, and then share what was accomplished. This is meant to provide an opportunity for participants to articulate clear goals that are feasible within the given time slot.

As recurrently mentioned by our informants, the flexibility associated with being self-employed, or being allowed to work remotely can be challenging as it requires individuals to establish and maintain their schedule independently. By providing a clear structure, complete with plans and breaks, Hoffice alleviates some of that burden. Prior work has described the strategies people adopt to separate, or not, work and life (Nippert-Eng 2005), the continuous reconfiguration of work-life boundaries (Gregg 2013) and how separating work and life can, in some cases, be conceptually difficult and practically undesirable (Leshed et al. 2014). Attending Hoffice events serves as an effective and collaborative way to create such boundaries, and clearly mark when a work day begins and ends. Following the structure - and pairing out one's work into smaller tasks to be undertaken within short sessions - helps participants feel accomplished. As discussed during the interviews and the focus group, by putting emphasis on celebrating together the work that got done, rather than worrying alone over everything that did not, Hoffice reduces (or even alleviates) feelings of guilt and sustains long-term wellbeing and efficiency. Key to achieving this is the combination of setting feasible goals, working in a concentrated, structured manner, and taking social breaks that often involve also physical activity. This structure is meant to make Hoffice days effective without draining the participants, and based on our observations, this seems to be the case for active Hoffice goers. As one of them described: "I'm not exhausted when I get out of here".

The central importance of the structure for what makes Hoffice an inspiring concept is visible in how the structure has been adapted for use in spaces and for needs that differ somewhat from the original formulation. (Here, it should be noted that the structure was meant by the founders as a starting point for cocreation and experimentation, rather than a strict set of rules). For instance, hosts have set up events in libraries (Boffice, from the Swedish word biblioteket), the forest (Hoffice i Skogen), and online (Voffice, where the Virtual Hoffice involves no physically co-located activities but offers an online setting for articulating one's objectives, reporting on progress, and experiencing a sense of togetherness). Some people have started using the structure at their regular workplaces and/or at home with their partners, without opening the events up for the wider community. To sum up, events that rely on the Hoffice concept need not be organized in a private home by a private homeowner, even though this is still held as the gold standard within the community. 


\subsubsection{Technological Infrastructure}

When it comes to Hoffice, the use of networked technologies is normalized to the point that it "goes without saying". During our fieldwork, we have been continuously struck by how seamlessly Hoffice attendees set up to work in various locations and how rarely any mention of technology comes up in community members' accounts of their experiences of Hoffice. Yet, it is evident that the very existence of Hoffice depends upon an assemblage of networked technologies that enable both the creation and coordination of events and the work that takes place at them. The set of technologies that is central to Hoffice includes reliable, ubiquitous connectivity through smartphones and wi-fi networks, Facebook as a hub for connecting people to the community and coordinating participation, and the availability of laptops and cloud services that makes it easy and comfortable for participants to move work resources (i.e. documents) to different places. Overall, using such technologies seems straightforward for the participants: everyone brings a personal device and as long as there is wi-fi - be it the host's home network or a hotspot on a participant's smartphone - getting to work requires little technological setup. Our analysis shows that these efforts were limited to finding out the password for the wi-fi.

This highlights how the world of work has evolved since CSCW scholars first started examining nomadic work practices, and how many of the concerns they found nomadic workers struggling with at that time are non-issues in a context like Hoffice. Setting up to work at Hoffice differs from prior CSCW accounts of nomadic work practices. These earlier investigations illustrated, for instance, how placemaking was experienced as the extra work required to turn locations into amenable workplaces (Brown and O'Hara 2003; Rossitto and Severinson Eklundh 2007; Perry et al. 2001), that planning and orchestrating the use of constellations of technologies was an essential aspect of nomadic work (Rossitto et al. 2014), and that creating and maintaining the mobile office was a main concern for nomadic workers (Su and Mark 2008). Such differences can certainly be explained in terms of the different settings different studies have focused on. Hoffice, for instance, lacks a strict organizational structure and this makes it possible for participants to use the technologies they prefer. However, it is worth noting that over the past years, the rapid evolution of mobile computing and a variety of cloud services has made the circulation of working resources and artefacts easier to plan and manage. Thus, compared to the investigations above, the socio-technical practices around the mobilization of work (Perry et al. 2001) are normalized in the case of Hoffice to the point of becoming unremarkable for participants. In this vein, smartphones play an integral and indicative role in the practical arrangement of Hoffice events: when participants are making their way to a Hoffice event, the experience is smooth largely thanks to the availability of connected devices that can be used for navigation as well as for messaging about small but crucial details such as door codes. This tends to go unnoticed if nothing goes wrong - very much in line with the idea that infrastructures are embedded and transparent, and only become visible upon breakdown (e.g. Bowker et al. 2016; Star and Ruhleder 1996). 
An important practice that Facebook facilitates is private messaging between the host and those who have signed up for events. For instance, on the day before the first author was going to attend a Hoffice event hosted by a person she had not met before, the host sent a private Facebook message to all the guests to share his professional LinkedIn profile. He also included information about the floor on which his apartment was located, the availability of coffee and of nearby lunch restaurants. These first-contact online practices are an important way to welcome guests and introduce them to the physical home and to the person(s) living there. Interestingly, they were so obvious to Hoffice participants that they were not mentioned during the interviews and the workshops, and only became visible through participant observation. Similar to negotiations over network hospitality in the context of platforms such as Couchsurfing and Airbnb (Lampinen 2014; Ikkala and Lampinen 2015), this backand-forth messaging between the host and the guest functions as a way of establishing interpersonal trust and paves the way for face-to-face interactions.

\subsubsection{Home as a Shared Workplace}

Sharing one's home by turning it into a collective - even if only temporary workplace, is a core aspect of Hoffice. In setting up an invitation for a Hoffice event, the host usually sets a maximum for how many people can attend. This is, in most cases, determined by the size of the apartment and the number of work stations available. Work stations can be seats by a dining table or spots on the couch anything that the host deems fit to serve the purpose. Considerations over how many guests can be accommodated are reminiscent of those that Couchsurfing hosts make in determining what, to them, constitutes sufficient space for hosting and how, in turn, they can ensure that guests arrive with realistic expectations regarding the space that will be available to them (Lampinen 2016).

The arrangements that are made when opening up domestic space for members of the local Hoffice network tend to be straightforward and pragmatic. For instance, hosts can make key information, such as the names of wireless networks and their respective passwords, easily accessible to all attendees by writing them on a blackboard or a large sheet of paper. These are usually left available so that guests can easily refer back to them when needed.

Beyond practical considerations, taking part in a Hoffice event for the first time or for the first time with unfamiliar people - can feel challenging for both the guests and the host: people might have concerns regarding safety but also anxieties about awkwardness or discomfort. This, however, relates more to how enjoyable interactions are than to concerns about more drastically adverse experiences. Attendees choose to put these hesitations aside and, as one participant put it during a lunch interview, consciously opt for trusting other people and coming together with them. While not everyone is comfortable with the idea of taking part in these types of activities, some are. As one, rather extreme, example of Hoffice hosts' willingness to open up their homes, a participant told us that she was once booked for an emergency doctor appointment on the very morning she was supposed to be hosting a Hoffice 
event at her place. She described how she had sent out a message to all guests to let them know about this change of plans but, since the notification went out quite late, she bumped into one of the guests on her way out. To solve the situation in a hospitable way, she decided to give the guest - a person she had never met before the keys to her apartment so that he could let himself in. This is clearly an exceptional case even within the Hoffice network, and we are not suggesting that many of those involved would be willing to do anything like this. Based on research, it is very unusual for hosts not to be present at Hoffice events. Still, the incident shows the extent to which some network members can be comfortable with letting people into their home.

A challenge for those who are willing to host Hoffices might be the separation between work and life at home, particularly the presence and the preferences of family members or housemates. Several of our informants explained that at some point they had had to stop hosting Hoffices due to the presence of babies or small children, or because their spouse did not like the idea of unfamiliar people spending time at their home. Where hosting remained possible, we learned that family members had negotiated days on which the person involved in the Hoffice network could have the place for themselves and host events. Here, again, the practice is similar to negotiations regarding network hospitality (Lampinen 2016) where household members needed to come to a consensus about whether, when, and who they were willing to welcome to their home. In such negotiations, each household member was typically given the power to veto any hosting plans. Thus, the boundaries of hosting were essentially set by those most reluctant to open up the home and, where visits were arranged, those most enthusiastic to host agreed to shoulder most of the effort involved in welcoming guests.

\subsection{Participatory Efforts to Get Individual Work Done}

In the sections above, we have covered the basics of how Hoffice events are arranged in terms of schedule, space, and technology. Below, we turn to another key aspect of Hoffice, that is the participatory efforts to get individual work done. This constitutes a departure from traditional CSCW investigations of collocated work where the articulation of work around interdependent, collaborative activities has been paramount to both analytical purposes and subsequent design efforts (e.g. Normark and Randall 2005; Luff and Heath 1998; Luff et al. 2000).

We characterize Hoffice events as participatory (Delwiche and Henderson 2013) in the sense that each participant's contribution is valued, and that connection with and care for other participants are central to the experience of taking part in Hoffice events. While, as we will see below, Hoffice events require everyone's contribution to be enjoyable and rewarding, work-related activities usually undertaken during work sessions are typically not interdependent. (This in contrast to scholarship that focuses on collaborative work where challenges stemming from interdependence are a key issue, see, e.g. Bannon and Schmidt 1989; Schmidt and Bannon 1992.) Rather, 
collaboration at Hoffice unfolds in the form of collective efforts to enable each attendee to accomplish their own goals. By describing Hoffice as a participatory rather than a collaborative - ensemble, we draw attention to each member's contribution and responsibility to co-create a setting that fosters social and emotional support to get individual (rather than collaborative) work done. In what follows, we further unpack the participatory nature of Hoffice events by focusing on two core aspects of the community: planning togetherness and internalizing the norms of the community.

\subsubsection{Planning Togetherness}

The paramount motivation to attend Hoffices is to come together to work in the company of other people. Both during the workshops and the interviews, our informants privileged this aspect of the community, without bringing up any challenges related to the practical achievements of coming together (for instance, troubles with wireless connectivity or hassles in bringing along necessary working resources). The togetherness that participants seek serves an instrumental role: being physically collocated is experienced as a way to find the concentration and discipline necessary to carry out work-related tasks effectively. In this sense, being together provides a more efficient alternative to working at home, in isolation and without support for structuring one's schedule and plans. Two of the participants in the first workshop provided us with extreme examples in this regard. One explained that during the period when she was finalizing her book project, she attended Hoffices regularly enough to make her home office redundant. Another described how, on a number of occasions, he had spent a long time commuting into the city in order to attend Hoffice events:

'I live in [a smaller town outside of Stockholm], so if I go to a Hoffice I have to travel for quite a stretch, so I used to travel for two and a half hours to go there, and two and a half hours to return home, but it was worth it. [...]. The reason I do it is that, without any doubt, I get four working days out of just one. And I think that the reason is that we use group pressure in a positive way. Some people may think that group pressure is negative, but if one uses it in the right way, it is good.' (Allan).

Although most attendees did not commute for such a long time, the connection between being together and working effectively was a recurrent theme in the data collected. As the quote indicates, being with other people serves as a positive reinforcement to get things done during a work day.

However, there is more to motivate attendance than just improved work performance. Many participants talked about how they had met interesting, new people through the network. For many, these were casual acquaintances, but we also heard about friendships and possible professional contacts, while one participant even credited Hoffice for his new romantic relationship. Some appreciated the break 
activities as a source of improved physical well-being, describing how after a day at the Hoffice, they did not feel as drained as they tended to feel after a day at a regular office or at home.

The shared motivations and practices that are characteristic of how Hoffice events are co-created are key to contributing to a sense of togetherness. This makes working at Hoffice substantially different from working, for instance, in coffee shops (Liegl 2014) where the lack of a shared schedule and work structure dissolves the participatory dimension of being together.

\subsubsection{Internalizing the Code}

Coming together is not without its problems, and discussing these troubles brings us to the importance of norms in creating and fostering the emerging culture of Hoffice. As previously introduced, the Hoffice structure serves to establish a shared rhythm of working sessions and breaks, while prompting attendees to explicate immediate and concrete work objectives. Here, we consider the role the structure plays in creating boundaries around work, and in nurturing a sense of belonging to the community which was mostly associated with the internalization of central Hoffice norms.

Firstly, while Hoffice events are co-created by everyone in attendance, some roles are more demanding than others. As participants in the workshop recounted, events need a host (who makes the invitation and offers the space to be used), a facilitator (who is responsible for helping the group to follow the work structure and managing the breaks), and guests (who contribute by showing up, following the structure, and sometimes by providing ideas for the break activities). The same person usually serves as both the host and the facilitator. Managing both roles is, however, a demanding task that can get in the way of the hosts' ability to focus on their own work. This is problematic, as a key motivation for hosting a Hoffice event is the opportunity to work along the Hoffice rhythm. A common complaint from experienced Hoffice attendees, particularly hosts, concerned novice members' failures to adhere to the Hoffice culture. For instance, participants shared stories of attendees commenting on what others had achieved (or not) during specific work sessions. This was deemed as something to be avoided, since check-in rounds are meant to assist people in articulating their plans and progress, rather than evaluating the session outcomes.

A second, related issue concerns the ability to articulate one's own objectives briefly. For instance, one of our workshop participants valued the check-in rounds, as hearing that others, too, are tackling specific tasks creates a sense of being in it together. However, she felt that it is uninteresting and irrelevant to hear the specific details of what people are going to do. Attendees who share too much on check-in rounds simply do not get the code. The articulation of plans for a work session is strictly for the benefit of the individual, not an effort to explain one's work to other attendees. 
'It is interesting to listen to [other people] during lunch, but to hear the details of what they are supposed to do now [during a work session] is completely uninteresting to me; I'm here to work, but it is however interesting for me to hear that they have a task that needs to be undertaken, because then I'm also on it...you see this is the structure. Maybe this should be clarified because there have been times when I felt, not annoyed, but I felt that someone doesn't quite get the code.' (John)

The value of this became quite tangible during one of our participant observations, when the host - a Hoffice novice - kept mentioning specific work processes that were difficult to understand for most of the attendees.

A third concern relates to failures to understand and respect the separation between silent working time and social breaks. As we learned, this had caused an intense discussion which had inspired two core members of the community to write a short document on proper Hoffice behavior, and to share it on the Facebook group to help socialize newcomers to the expectations and practices of the Hoffice network. Here, it is worth noting that togetherness is experienced in conjunction with an obligation to relate to other people and establish a relationship with them, even if this is limited to the short breaks. In this vein, several participants described how they explicitly avoid talking too much about their work even during breaks. This helps establish breaks as a genuine moment of setting work aside and engaging with other attendees on a different level.

What is at stake is a way of understanding one's participation as consequential for other people and for the atmosphere of the event. Trouble in meeting these expectations was often associated with new members, and their inability to grasp what the meaning of the structure really is and how it intertwines with everyone's efforts to make a Hoffice day successful. This was a source of tension that sometimes degraded the experience of being together. In the following quote, a host recounts his experience of a Hoffice day that did not work out as expected:

'It has happened that people have been [at Hoffices] because it is a social thing, they think it's cool to sit and babble, and then when the break is over they keep on talking; and this is indeed the reason I think it has been difficult, since I thought I had clear rules or that I had said how Hoffice thinks [that things should be done].' (Martin)

While failures to internalize and respect norms was a source of frustration and concern for most of our participants, we initially found it somewhat prescriptive. It was only during a participant observation that we realized how the whole experience can break down when only a few people follow the structure, and the basic norms of being silent and acknowledging the presence of other people are disregarded. During a Hoffice event at the local library that both authors attended, it was clear from the beginning that rather than following the structure, other attendees were interweaving work and socializing in a less structured manner. This meant, for instance, that only 
three of the six attendees (including the two authors) stated their intentions before any work session, and then had breaks and lunch together. It also meant that the room was not silent during work sessions as the other attendees repeatedly talked with one another, played loud sounds from their laptops, and came in and out of the room several times. Their non-participation in the shared structure undermined the opportunity to relate to other people, acknowledging their presence and enjoying their company.

\subsection{Co-Creating an Alternative Social Model}

When it comes to Hoffice, the co-creation of an alternative workplace is the outcome of participatory efforts aimed at sharing a physical space (a home) and at nurturing a social dimension of work. On the simplest level, this relies on there being people who are willing to become hosts and guests of Hoffice events. On a more interpretative level, the co-creation of temporary co-working spaces draws attention to the values and expectations that constitute the Hoffice culture.

Fostering trust between individuals, encouraging self-actualization, and remaining open to new acquaintances and interactions are key tenets of Hoffice. While these values can sometimes be in tension, they are crucial both to the vision of Gradin Franzén, the co-founder of the Hoffice network, and to more peripheral members' accounts of participating in the community.

In the following sections, we draw attention to trust, self-actualization, and openness to new acquaintances. We consider Hoffice as an alternative social model that seeks to address challenges associated with flexible forms of work. The central values of trust, self-actualization, and openness contribute to the idea that sharing resources and engaging in self-organizing events have the potential to reposition people as valued members of their local communities, and as active co-creators of their working conditions. The situated practices around sharing homes and cocreating workplaces make Hoffice an alternative social model that challenges the frame of workplaces as sites associated with profit, competition, and managerial structures.

\subsubsection{Fostering Trust between Individuals}

Belonging to a supportive community was a recurring aspect in Hoffice members' accounts of why they had been attracted to the network in the first place, and why they kept on participating in the community. The care that such a community can offer is a central objective of Hoffice. It is often manifested in helping others be productive but also in refraining from judgment when it comes to what others are doing and how much they are accomplishing. Moreover, collaborative efforts to take care of everyone in attendance include breaks that acknowledge that knowledge workers are more than just brains-on-a-stick and that they feel better when their work day features movement, too, be it a short walk, some stretching, or a few minutes of dancing to finish off the lunch break. In a circular fashion, these acts serve to establish 
trust between the participants, but the more the participants already trust each other, the better they tend to be able to receive and offer such care to one another.

Placing trust in other people is central to the culture of Hoffice. This entails, for instance, confidence in that others, including complete strangers, can be kind and that opportunities to laugh with them - even about oneself - are to be embraced:

'For me, it's about building this trust and openness in groups and I often find that structured activities are better. People playing a game together they feel closer afterwards than if we would have had a group discussion or just having coffee together because, then, they share a laugh and they do something a little bit outside of their comfort zone, and then even though they don't know much more about each other they feel more comfortable.' (Gradin Franzén)

As recounted during interviews, co-creating break activities is a strategy that facilitators adopt to nurture trust. To prevent people from feeling uncomfortable doing activities they may find awkward (e.g. yoga positions), guests are actively encouraged to suggest what to do, thus empowering them to influence the activities and social interactions that take place during breaks.

This sense of trust is not a fixed quality of participation, but rather a feeling that evolves and develops over time as people familiarize with each other. For instance, during one of the interviews a participant told us about an occasion when attendees took longer breaks and engaged in a playful music jam. While our study suggests that this was an isolated case, the incident illustrates how repeated participation results in learning to know other people and, eventually, trusting that something can be achieved collectively.

Sharing a purpose is another aspect that fosters trust in the Hoffice community. On a basic level, this is evident in the collective efforts to make the event work, thus giving all participants the best possible opportunity to attain their personal goals. More profoundly, while attendees do not typically work together, they often still share an orientation to work in the form of shared values, such as an emphasis on doing personally meaningful work rather than maximizing one's income (if the two are in tension). This brings us to the second value, self-actualization.

\subsubsection{Bringing about a Setting that Encourages Self-Actualization}

Another repeating feature in empirical accounts of Hoffice is that it provides a space for a fuller expression and exploration of one's identity and its different facets. Emphasizing aspects of life and work, such as personal satisfaction and sense of self, is central to Hoffice as a cultural and social phenomenon, especially since some participants experienced that such values were not shared or acknowledged in traditional work settings.

In the quote below, one participant discusses her experience of contributing to a community and engaging with a different circle of people instead of giving too much importance to money and other economic issues: 
'I have several, often older persons, they just talk about pensions and how much money they make, and I haven't had, I've worked for myself and not paid much pension savings, it gives me so much anguish, so it's lovely to join such a company, in a way it's more about contributing, I actually think this is very important for me. I don't care if I've got a lot of money, just that I manage.' (Thilde)

Duringthe first workshop, this disregard for money was also discussed in relation to the tension between working for a living and engaging with a job that sparks personal interests, inner creativity, and personal fulfilment. Hoffice was described as a social space that nurtures creativity and motivation particularly with respect to secondary, part-time jobs regarded as meaningful yet difficult to engage with otherwise. The quote below illustrates this point as a participant describes her everyday work - what she calls a bread job, that is a job to put bread on the table - and her "side" project to write a book:

'The thing I like the most about Hoffice is to be my creative self, because I'm selfemployed, but I have a bread job just to support myself, and then it often happens that I'm not creative, that I'm making money instead; so to get on with my creativity, with what I want to do and to have fun, it's cool. When I go to Hoffice, I do not talk about my bread job and so on, this is [going to Hoffice] the thing I do as my own choice, this is what my heart desires: to write this book and do it here. Then my creativity becomes stronger, and that part of me, and this part of my identity. [...] I do not know if others feel [like] this, but I find that there is a lot of creativity and that we reflect on each other's creativity; it's not like this how the job should be done, but often this is the job I want to do'. (Johanna).

The relation to creativity and self-actualization was therefore regarded as a way to create one's own reality and, thus, to make change for oneself and for other people. This is something that most people did not feel they were getting from their regular employment, or from their solitary work arrangements. Hoffice serves as an alternative workplace that makes room for self-actualization by offering acceptance, acknowledgment, and care - and allowing individuals to contribute reciprocally by supporting others.

\subsubsection{Remaining Open to New Acquaintances and Interactions}

The third value, openness to new acquaintances, is key for accomplishing the first two. In a setting like Hoffice, trust or a fuller actualization of one's self could not emerge without openness to new acquaintances and interactions. Yet, remaining open is also important in its own right.

As previously discussed, the importance of being open is reflected in the choice of Facebook as the main platform, and in the practice of accepting new members to the group by default. An expectation of openness and inclusivity is deeply ingrained into 
the Hoffice concept: Hoffice is supposed to bring people together to work side by side, to help participants to get things done effectively, but also to provide a meaningful and comfortable social setting where one might make new acquaintances and benefit of a supportive sense of community. While experienced participants in our workshop wanted to retain the open culture, despite the rapidly growing number of network members, they explained that living up to this ideal felt at times too troublesome. Participants expressed appreciation of opportunities to make new connections - they did not want to turn away newcomers but they worried about how the community would survive its rapid growth. They described frustrating experiences where they felt too much time had to be spent on onboarding novice participants and explaining to them how Hoffice events typically unfold. Furthermore, they mentioned that the lack of stability and continuity in who attended events had made it hard to establish the kinds of supportive peer relations they were looking for from Hoffice.

Fast growth has made it hard to keep the community coherent. In this sense, the Hoffice community in Stockholm is a victim of its success. After receiving some visibility in the press, the number of members in the Facebook group has grown fast. The number of network members willing to host events has not increased in sync with this change, making it harder for people to find events to attend. Out of these pressures the community has started to fragment as some have chosen to organize events to which only selected people are invited, rather than being advertised on Facebook for the whole community. Fewer events on the main group makes it harder for newcomers to join the activities, learn the community's norms, and take on more active roles, for instance by hosting events. We will not explore these issues in length in this article but they are worth noting to remind readers that despite its appeal and early successes, Hoffice, like other self-organizing communities, is brought about through collaborative effort and sustaining it over time is not a simple task.

\section{Discussion}

The participatory practices inherent in Hoffice are an example of an alternative social model - a departure from the contemporary status quo of knowledge work. The idea of bringing about an alternative has its roots in how Hoffice was initially conceived and instantiated by two people who were struggling to carry out their independent work in the isolation of their homes. As we write this paper, this kind of alternative making is evidenced in the efforts of a broader group of Hoffice members to sustain the network.

Our study highlights how participants valued practices that help establish boundaries around work and recreate the sociality of work. Participating in Hoffice events provides a setting and the means to pursue these goals, thus contributing to the attendees' sense of agency, empowerment, and well-being. To conclude, rather than engaging with design implications on how to better support Hoffice, we seek to unpack what CSCW can learn from how Hoffice is already making change, and what 
the implications of this study are for future research within and beyond CSCW. We focus our discussion on how members make change through Hoffice, the politics of care Hoffice allows us to consider, and in what sense this might be applicable beyond the case at hand.

\subsection{Making Change through Hoffice}

Enacting and maintaining sustainable workstyles is central to Hoffice members. Attending Hoffice events creates both the physical space and the time to work on activities that are meaningful to the individual participants. Sharing a home with collocated Hoffice attendees enables individuals to accomplish their (work) goals with the support of others, rather than on their own. As seen in the findings, some attendees regarded participation as paramount to self-actualization and to being able to work on unpaid yet deeply meaningful tasks. This can be understood as a way of enacting change, both for oneself and for others - an issue that we discuss below.

Firstly, Hoffice provides a concrete context where participatory and collective efforts are directed at accomplishing individual work. In bringing together a group of people as hosts, guests, and facilitators, Hoffice co-creates a place and a community for work. This aspect is central to turning the "home office" into a "Hoffice" and to transforming the atomized reality of flexible work into a collective one. This aspect marks a profound difference from previous investigations of flexible forms of work (Barley and Kunda 2006; Bourne and Forman 2013; Gregg 2013; Gray et al. 2017) where managing work and life, allocating time, and maintaining relationships and contacts is often delegated to individual efforts.

Attending Hoffices enables individuals to get work done, but beyond that, alternating between work sessions and social breaks is instrumental to achieving a balance between efficient working and self-care. Since attending Hoffice is a choice rather than an obligation, and since emphasis is put on the sense of mutuality between attendees, we regard the co-creation aspects of Hoffice as participatory rather than collaborative. Participatory puts emphasis on the willingness and the value of each individual contribution (Delwiche and Henderson 2013; John and Wright 2015), yet it does not presuppose the interdependencies of work that are implied in the notion of collaboration (Bannon and Schmidt 1989; Schmidt and Bannon 1992). Hoffice's socio-technical infrastructure is mostly used to enable the participatory achievement of individual work, and here participation does not necessarily entail collaboration around the same work-related activity. Half way into the study, we arranged a Hoffice at our department to work on a paper together. This experience revealed to us the challenges that work interdependencies can pose on Hoffice co-working practices, turning the structure into a problem rather than an enabler. We found ourselves worrying, for instance, how not completing our stated goals might hinder the other person's writing. Moreover, it was difficult not to interrupt a co-author who was sitting at the same table and not to disturb other attendees with talk during work sessions. 
Secondly, Hoffice engages with change through providing social cohesion and support for people to come together. This entails values such as trust between community members, self-actualization, and openness to new acquaintances. These values are embedded in the design of the work structure, but it is only through repeated participation that people internalize them. Coming together to a shared, although temporary, workplace like Hoffice is empowering for its attendees, as it provides a social dimension for work that would otherwise be carried out alone. This constitutes a main difference from investigations of nomadic knowledge workers (Brown and O'Hara 2003; Perry et al. 2001; Su and Mark 2008; Liegl 2014) that illustrate how the struggle to recreate the sociality of work and to reconnect to the main office and colleagues is left to the initiative and resources of single individuals.

Thirdly, Hoffice provides an alternative form of togetherness, beyond consumption, as attending Hoffice events entails, by default, no monetary exchange. Guests may choose to contribute to coffee expenses or bring along food that is meant for sharing, but this happens within a frame of reciprocity, instead of being regarded as an instance of direct exchange. This reciprocal, non-monetary approach was one reason to prefer Hoffice to other co-working arrangements. Fees must be paid to access commercially operated co-working spaces where work stations can be rented. Additionally, our informants often lamented that spending a full working day at a coffee shop can get to be expensive. By steering away from economic exchange, Hoffice has the potential to make people less dependent on formal organizations and more connected to the communities around them, although these positives come with the caveat that socially oriented exchange may always exclude some, be it due to homophily or overt discrimination (Ikkala and Lampinen 2015).

Finally, Hoffice is an example of appropriating technology (particularly Facebook) to facilitate face-to-face encounters, rather than engaging in online interactions. The effort to tailor Facebook usage to work in this setting has been limited to creating and administrating the group's page. Hoffice mainly relies on the global platform to create events and to enroll new members. As we learned during the fieldwork, requests to join the local Facebook group are usually accepted, and no member has ever been asked to leave the group. This resonates with the idea of openness that underlies Hoffice, both as a concept and as a set of situated practices. Facebook allows any willing person to become a member of the Hoffice network, and it is through Facebook that initial connections are made. However, the encounters that make Hoffice meaningful take place face-to-face, in members' homes (or in other spaces that are being used to organize Hoffice events) and it is through repeated participation in such events that attendees develop a sense of community and an orientation to others.

Resonating with Håkansson and Sengers (2014), a people-lead initiative like Hoffice is valuable in that it highlights the challenges people encounter in their everyday life, while illustrating also how they can do things differently through collective action. This makes it interesting for CSCW scholars to examine the sociotechnical assemblage that constitutes Hoffice, including not only the situated 
practices, but also the mind set and values that are encompassed in Hoffice's participatory culture. While Hoffice may seem like a non-technical site of study, this is only because relevant technologies that underlie the activities are normalized and, as such, hiding in plain sight.

\subsection{Hoffice and the Politics of Care}

Hoffice provides a context for taking care of oneself and of other people. This is particularly significant with respect to the participants' experience of the challenges associated with flexible forms of work. Engaging in Hoffice as a self-organized and participatory enterprise repositions people as valued members of their local communities and as active designers of their work conditions. As seen in our study, this way of being is deeply intertwined with the Hoffice practices (e.g. following the structure and co-creating breaks), values (e.g. trust, self-actualization, and openness), and with the resulting sense of mutuality and orientation to others.

The experience of partaking in Hoffice, and thus shifting from the individual Nippert-Eng 1995; Barley and Kunda 2006; Gregg 2013,) to participatory efforts to co-create an effective and supportive context for work, is transformative of individuals and their spatial, temporal, cultural, and social contexts. Sharing an intimate space like a home becomes a way to (re)create a schedule for work and to attach a valued, social dimension to it.

Shifting the focus from sharing in terms of co-using material resources like homes to sharing as an act of caring and being together broadens our analytic possibilities. This point connects to the political nature of Hoffice as an alternative model of coworking. Hoffice is political in that it is concerned with the production of alternative workplaces that foreground togetherness and support, rather than solely profit or individual productivity. It embodies the effort to question a particular social situation (the experience of self-employment), the existing order of things (how individual, freelance work is carried out and accomplished), and the reconfiguration of social relations and boundaries (encountering others through the temporary sharing of a domestic space). To use a concept from Ranciére (2010), Hoffice is a way to "distribute the sensible": Hoffice promotes imagination of how the socio-cultural context of flexible forms of work could be different from what it is today. Rancière's conceptualization of politics presupposes that everyone (rather than only formal political groups) can engage with making change, and that this is influenced by what is seen as sensible, that is, what we have come to know about a certain social order (Ranciére 2010; John and Wright 2015). Here, politics can emerge from ordinary everyday activities, and not merely from formal political settings and moments (Korn and Voida 2015). An event or an action is political because its form clashes with a certain existing reality and how we experience it - what Ranciére (2010) defines as "accessing the sensible".

CSCW, particularly at its intersection with participatory design, has traditionally been concerned with the politics of design. The involvement of users as co-designers 
of socio-technical systems (Bødker et al. 2010; Kensing and Blomberg 1998; Robertson and Simonsen 2013; Robertson and Wagner 2013) and efforts to democratize the workplace are an example of this political orientation. Reflecting on Hoffice's political qualities offers a different set of insights for CSCW research. Hoffice envisions a way to come together with the help of normalized networked technologies. This puts emphasis on the quality and meaning of interactions between people, rather than technological design. We argue that this emphasis is the transformative and, thus, political essence of Hoffice: by bringing together a network of people one can trust, Hoffice provides an alternative way of framing socio-technical practices at the workplace.

This tightly relates to Hoffice's concern for care, and to what we refer to as the politics of care. For Hoffice attendees, care manifests in self-actualization and engagement with meaningful projects. Yet, care is also an orientation to acquaintances, a genuine interest towards them (within the limits of the situation), and the effort to create, for them and with them, a favorable work context. In this sense, care is interdependent and relational, and it presupposes the presence and commitment of other people. Light and Akama $(2014,2017)$ have argued for a notion of care as a dialogical relationship imbued with qualities such as mutuality, trust, and openness towards other people. Their framing of care is targeted at discussing how participatory design projects can establish and maintain relationships with communities. For us, it resonates with the core values of the Hoffice community. Sharing a home, a working day, or even just a short break can provide opportunities to sensitize to each other and to develop the sense of trust that reflects on people's willingness to continue their participation. Care presupposes interdependencies and intra-actions (Barad 2003; Suchman 2007) as a pre-condition of coming together, becoming together, and creating relationships with others (Puig de la Bellacasa 2012). In Hoffice, care is not an abstract moral value, but an interactional quality emerging from the situated practices and the internalization of the values and norms that are core to the community.

Talking about the politics of care draws attention to a narrative (Ingold 2006) of the workplace where fulfilment, self-actualization, togetherness, reciprocal support, and participation (rather than just collaboration) are central, alongside profit, productivity, and efficiency. Ultimately, this foregrounds the social and human nature of workers, rather than focusing solely on the economic value of their labor.

\subsection{Implications for $\mathrm{CSCW}$ Research}

A panel discussion on critical approaches to the changing workplace at the ECSCW 2017 conference (Holten Møller et al. 2017) asked how CSCW research can and could rethink workplaces and supportive technologies by focusing on the value of life, rather than collaboration and work efficiency. In what follows, we articulate one answer to this question while highlighting how Hoffice contributes to CSCW research. 
What does it mean to orient design towards the politics of care? What would it mean to design for the changing workplace with a focus on care, rather than connectivity, efficiency, or flexibility? A practical and empirical exploration of these questions could take the shape of adapting the Hoffice methodology to various settings and differing needs. As noted in the analysis, some members have taken the initiative to export and adapt the Hoffice structure to different contexts. Hoffice events have been organized in public places like libraries or online with attendees connected via Skype. This exemplifies how Hoffice's focus on care can be translated to other settings. Resonating with this, we have discussed with Gradin Franzén the design of Hoffice with childcare for independent contractors juggling work and family, or Hoffice held in third-places (e.g. libraries or community centers) meant for job-seekers, or other groups of people who might benefit from such a supportive social context (e.g. economic or political migrants). Another related question concerns what it would mean to design for the politics of care in workplaces characterized by an individualistic and competitive culture (e.g. contemporary universities) or, as seen, within corporations relying on flexible forms of work and independent contracting (Perry et al. 2001; Brown and O'Hara 2003; Barley and Kunda 2006; Su and Mark 2008; Bourne and Forman 2013; Gregg 2013; Gray et al. 2017) where the efforts to stay connected to the homebase are typically delegated to individuals.

On a conceptual level, this implies reframing a number of core tenets of the research program on Computer-Supported Cooperative Work. Previously, there have been suggestions to focus on human-centered design (Bannon 2005), designing for all of us rather than for them (Light and Akama 2017), and building long-term relationships with participants (McCarthy and Wright 2015). We suggest that an orientation towards the politics of care redefines the meaning ascribed to central members of a community. Being at the center of a community that cares entails facilitating others to achieve their goals and well-being. As such, it brings attention to a set of values and ways of being together, rather than to the acquisition of professional skills. Relatedly, it presupposes an orientation towards design sensitivities, rather than methods (Dombrowski et al. 2016), including questions about fulfillment, compassion, constructive intimacy, and creativity (Light and Akama 2017).

The lack of a management structure makes Hoffice very different from traditional workplaces. Next to increased responsibilities, this provides freedom, in the sense that attendees felt they could focus on the work they wanted to do, rather than on how it should be done, and that they could take the initiative to adjust the structure, export it to different settings, or experiment with reconfiguring central roles. For instance, during the first workshop, one participant told us about his experience of sharing the responsibility of organizing a Hoffice with a friend, so that one was the facilitator of the event, and the other one the host. While changes are usually discussed with other attendees, the negotiation processes are informal and not as structured as they tend to be within a formal organizationa. The organization of the workplace is, thus, replaced by a network of peers who share the purpose to support each other while engaged in their own specialized work. While some serve as hosts and facilitators, Hoffice 
activities start from the expectation that participants co-create their temporary workplace through participatory effort where the contribution of each participant is important and valued. This echoes Germann Molz's (2014) call for complicating the notions of guest and host in the context of Couchsurfing since, in practice, these seemingly distinct roles can blur into a collaborative activity. Based on our study, such blurring is usual at Hoffice events and making it more visible can be a way to carve out room for individuals to participate actively in the co-creation of the workplace, especially when they are still new to the network.

Finally, the lack of a formal, organizational structure brings to the picture a number of potential complications that are not tackled by Hoffice, at least not in its current form. Complementary to the politics of care discussed above, these issues approach a more classic view of politics, that is, the regulation of social life through rules and laws that apply to members of specific groups. Sharing is a cultural discourse and a practical phenomenon (John 2017; McLaren and Agyeman 2015). When it comes to Hoffice, sharing homes intertwines with trust, togetherness, wellbeing, and openness. This is what makes the network attractive, at least to its most active members. However, a more holistic discussion of its sustainability and impact over time also needs to encompass issues such as safety in the workplace, ergonomic and health standards, insurance policies, respect for licit working hours, and the awareness of policies that regulate the presence of strangers or acquaintances in domestic spaces. These are all essential concerns of work life that should not be left on the shoulders of single individuals, even when they take it upon themselves to make change in an effort to move towards more desirable work styles.

\section{Conclusion}

In this paper, we have introduced the self-organizing network Hoffice. The concept relates to a co-working methodology and to the set of practices inherent in opening up one's home as a temporary, shared workplace, with the help of existing social media platforms, particularly Facebook. We have discussed both practices of cocreating temporary workplaces, particularly for workers who lack a stable office and orchestrate flexible work arrangements, and the values and rhetoric enshrined in Hoffice. Moreover, we have illustrated the connections between Hoffice and studies of network hospitality, two domains where networked platforms are used to facilitate encounters in domestic spaces.

Our findings draw attention to i) the practical arrangement of Hoffice events, including the role of the work structure, the technological infrastructures that enable Hoffice, and the use of domestic spaces; ii) participatory efforts to get individual work done, and iii) the co-creation of an alternative social model that encourages trust, self-actualization, and openness.

Our investigation invites CSCW scholars to revisit what is means to study the workplace in a changing world of work. We highlight that Hoffice is already making change for its members by providing a context for more sustainable work styles, 
particularly with respect to the challenges emerging from flexible work arrangements (e.g. self-managing work load and schedule, the lack of a social context, flexibility in hours and income, etc.). Finally, we have discussed Hoffice as a model for a workplace that values self-care and care for others, and how this case can inspire $\mathrm{CSCW}$ research to develop new visions of the workplace, building on the politics of care, instead of - or as a complement to - connectivity, profit, and productivity.

\section{Acknowledgements}

We would like to thank Christoffer Gradin Franzén, all the workshop participants and the Hoffice members we have interacted with for sharing their experience, and for contributing to an engaging and interesting discussion. We also thank Daniel Pargman for early discussions about studying Hoffice, and Stockholm University for supporting this project with the "Collaboration Grant SA2016-21".

Open Access This article is distributed under the terms of the Creative Commons Attribution 4.0 International License (http://creativecommons.org/licenses/by/4.0/), which permits unrestricted use, distribution, and reproduction in any medium, provided you give appropriate credit to the original author(s) and the source, provide a link to the Creative Commons license, and indicate if changes were made.

\section{References}

Ackerman, Mark; and Elizabeth Kaziunas (2017). A new generation of CSCW: Reinvigorating $\mathrm{CSCW}$ field-based research through a theory-inspired reboot. In: ECSCW '17. Proceedings of 15th European Conference on Computer-Supported Cooperative Work - Exploratory Papers, Reports of the European Society for Socially Embedded Technologies, Vol. 1, No. 2, pp. 238-255.

Bannon, Liam. J. (2005). "A human-centred perspective on interaction design." In A. Pirhonen; H. Isomaki; C. Roast; and P. Saariluoma. (eds), Future interaction design, London: Springer, pp. 3151.

Bannon, Liam; and Kjeld Schmidt (1989). CSCW: Four characters in search of a context. In: ECSCW 89. Proceedings of the First European Conference on Computer Supported Cooperative Work, Gatwick, London, 13-15 September 1989, pp. 358-372.

Barad, Karen (2003). Posthumanist performativity: Toward an understanding of how matter comes to matter. Signs: Journal of Women in Culture and Society, vol. 28, no. 3, pp. 801-831.

Barley, Stephen; and Gideon Kunda (2006). Gurus, hired guns, and warm bodies. Itinerant Experts in a Knowledge Economy. Princeton University Press.

Bialski, Paula (2012). Technologies of hospitality: How planned encounters develop between strangers. Hospitality and Society, vol. 1, no. 3, February 2012, pp. 245-260.

Bjørn, Pernille; Luigina Ciolf; Mark Ackerman; Geraldine Fitzpatrick; and Volker Wulf (2016). Practice-based CSCW research: ECSCW bridging across the Atlantic. In D. Gergle; M. R. Morris; P. Bjørn; and J. Konstan (eds): CSCW'16. Proceedings of the 19th ACM Conference on Computer Supported Cooperative Work and Social Computing Companion (CSCW '16 Companion), San Francisco, CA, USA - 27 February - 2 March 2016, New York: ACM Press, pp. 210-220.

Bødker, Susanne; Pelle Ehn; Dan Sjögren; and Yngve Sundblad (2010). Co-operative Design perspectives on 20 years with 'the Scandinavian IT Design Model'. In NordiCHI '10. Proceedings 
of NordiCHI 2010. Keynote presentation. https://www.lri.fr/ mbl/ENS/DEA-IHM/papers/ Utopia.pdf

Bogdan, Cristian; Chiara Rossitto; Maria Normark; Pedro Adler Jorge; and Kerstin Severinson Eklundh (2006). On a mission without a Home Base: Conceptualizing Nomadicity in student group work. In: P. Hassanaly; T. Hermann; G. Kunau; and M. Zacklad (eds): COOP '06. Proceedings of COOP 2006, the 7th International Conference on the Design of Cooperative systems, France, Provence. The Netherlands: IOS Press, pp. 23-38.

Bossen, Claus; and Martin Foss (2016). The collaborative work of hospital porters: Accountability, visibility and configurations of work. In D. Gergle, M. R. Morris, P. Bjørn and J. Konstan (eds): CSCW'16. Proceedings of the 19th ACM Conference on Computer-Supported Cooperative Work and Social Computing,San Francisco, CA, USA, 27 February - 2 March 2016. New York: ACM Press, pp. 965-979.

Bourne, Kristina; and Pamela J. Forman (2013). Living in a culture of overwork: An ethnographic study of flexibility. Journal of Management Inquiry, vol 23, no 1, March 2013, SAGE, pp. 68-79.

Bowker, Geoffrey C.; Stefan Timmermans; Adele Clarke; and Ellen Balka (2016). Boundary objects and beyond: Working with Leigh star. Cambridge Massachusetts, London England: The MIT Press.

Brown, Barry; and Kenton O'Hara (2003). Place as a practical concern of mobile workers. Environment and Planning A, vol. 35, no. 9, September 2003, pp. 1565-1587.

Bryman, Alan (2012). Social Research Methods. Oxford University Press

Buchberger, Sonja (2012). Hospitality, secrecy and gossip in Morocco: hosting Couch Surfers against great odds. Hospitality \& Society, Vol. 1, No. 3, 16 February 2012, pp. 299-315.

Czarniawska, Barbara (2014). Nomadic work as a life-story plot. Computer Supported Cooperative Work (CSCW), vol. 23, no 2, April 2014, pp. 205-221.

de Carvalho, A. Fabiano P. (2014). "Collaborative work and its relationship to technologicallymediated Nomadicity,". In C. Rossitto; L. Ciolfi; D. Martin; and B. Conein (eds): COOP '14. Proceedings of the 11th international conference on the Design of Cooperative Systems, Nice (France), 27-30 May, 2014 Springer International Publishing, pp. 209-224.

de Carvalho, A. Fabiano P.; Luigina Ciolfi; and Breda Gray (2017). Detailing a Spectrum of motivational forces shaping nomadic practices. In P. C. Lee; S. Poltrock; L. Barkhuus; M. Borger; and W. Kellogg (eds): CSCW'17. Proceedings of the 20th ACM conference on computersupported cooperative work and social computing, Portland, Oregon, USA, 25 February - 1 March 2017. New York, ACM Press, pp. 962-977.

Delwiche, Aaron; and Jennifer Henderson (2013). The participatory cultures handbook. New York: Routledge, Taylor and Francis Group.

Dewalt, Kathleen; and Billie Dewalt (2002). Participant observations. A Guide for Fieldworkers. Altamira Press.

Dombrowski, Lynn; Ellie Harmon; and Sarah Fox (2016). Social justice-oriented interaction design: Outlining key design strategies and commitments. In M. Foth, W. Ju, R. Schroeter, S. Viller (eds): DIS '2016. Proceedings of the 2016 ACM Conference on Designing Interactive Systems, Brisbane, QLD, Australia, 4-8 June 2016. New York: ACM Press, pp. 656-671.

Fatterman, Daniel (2010). Ethnography: Step by step. Third Edition. SAGE Publications Inc.

Gray, Breda; Luigina Ciolfi; Fabiano P. de Carvalho; Anthony D'Andrea; and Lisa Wixted (2017). Post-Fordist reconfigurations of gender, work and life: Theory and practice. British Journal of Sociology, vol 68, no. 4, pp. 620-642.

Gregg, Melissa (2013). Work's intimacy. John Wiley and Sons.

Grudin, Jonathan (1988). Why CSCW applications fail: Problems in the design and evaluation of organizational interfaces. In I. Greif: CSCW'88. Proceedings of the 1988 ACM conference on Computer-supported cooperative work, Portland, Oregon, USA, 26-28 September 1988. New York: ACM Press, pp. 85-93. 
Håkansson, Maria; and Phebe Sengers (2014). No easy compromise: Sustainability and the dilemmas and dynamics of change. In R. Wakkary; S. Harrison; C. Neustaedter; S. Bardzell; and E. Paulos (eds): DIS'2014. Proceedings of the 2014 conference on Designing interactive systems, Vancouver, BC, Canada, 21-25 June 2014. New York: ACM Press, pp. 1025-1034.

Holten Møller, Naja; Irina Shklovski; Six Silberman; Lynn Dombrowski; and Airi Lampinen (2017). A constructive-critical approach to the changing workplace and its technologies. ECSCW '17. In Proceedings of 15th European Conference on Computer-Supported Cooperative Work - Panels, Posters and Demos, Reports of the European Society for Socially Embedded Technologies, Vol. 1, No. 3, pp. 2510-2591.

Hughes, John; David Randall; and Dan Shapiro (1992). Faltering from ethnography to design. In M. Mantel and R. Baecker (eds): CSCW '92. Proceedings of the 1992 ACM conference on Computersupported cooperative work, Toronto, ON, Canada, 1-4 November 1992. New York, ACM Press, pp. 115-122.

Ikkala, Tapio; Airi Lampinen (2015). Monetizing network hospitality: Hospitality and sociability in the context of Airbnb. In D. Cosley; A. Forte; L. Ciolfi; and D. McDonald (eds): CSCW'15. Proceedings of the 18th ACM conference on computer supported cooperative work and social computing, Vancouver, BC, Canada,14-18 March 2015. New York: ACM Press, pp. 1033-1044.

Ingold, Tim (2006). Walking the plank: Meditations on a process of skill. In Defining Technological Literacy, towards an epistemological framework. New York: Palgrave Macmillan, pp. 65-80.

James, Al (2014). Work-life 'balance', recession and the gendered limits to learning and innovation (or, why it pays employers to care). Gender, Work and Organization, vol. 21, no. 3, pp. 273-294.

John, Nicholas A. (2017). The age of sharing. John Wiley \& Sons.

Kensing, Finn; and Jeanette Blomberg (1998). Participatory design: Issues and concerns. Computer Supported Cooperative Work (CSCW), vol. 3, no. 4, pp. 167-185.

Kleinrock, Leonard (1995). Nomadic computing - an opportunity. ACM SIGCOMM Computer Communication Review, vol. 25, no. 1, pp. 36-40.

Kleinrock, Leonard (1996). Nomadicity: Anytime, anywhere in a disconnected world. Mobile Networks and Applications, vol. 1, no. 4, pp. 351-357.

Korn, Matthias; and Amy Voida (2015). Creating friction: Infrastructuring civic engagement in everyday life. In O. Bertlsen, K. Halskov, S. Bardzell, O. Iversen (eds): AA'15. Proceedings of The Fifth Decennial Aarhus Conference on Critical Alternatives, Aarhus, Denmark, 17-21 August 2015. Aarhus University Press, pp. 145-156.

Lampinen, Airi M. (2014). Account sharing in the context of networked hospitality exchange. In S. Fussell; W. Lutters; M. R. Morris; and M. Reddy (eds): CSCW '16. Proceedings of the 17th ACM conference on Computer supported cooperative work and social computing, Baltimore, MD, USA, 15-19 February 2014. New York: ACM Press, pp. 499-504.

Lampinen, Airi. (2016). Hosting together via Couchsurfing: Privacy management in the context of network hospitality. International Journal of Communication (IJoC), vol. 10, no. 20, pp. 15811600 .

Lampinen, Airi; and Barry Brown (2017). Market design for HCI: Successes and failures of peer-topeer exchange platforms. In G. Mark; S. Fussell; C. Lampe, m.c. schraefel; J. P. Hourcade; C. Appert; and D. Wigdor (eds): CHI' 17. Proceedings of the 2017 CHI Conference on Human Factors in Computing Systems, Denver, CO, USA, 6-11 May 2017, New York: ACM Press, pp. 4331-4343.

Lauterbach, Debra; Hung Truong; Tanuj Shah; and Lada Adamic (2009). Surfing a web of trust: Reputation and reciprocity on CouchSurfing.com. In CSE '09. Proceedings of the international conference on computational science and engineering, New York, 29-31 August, IEEE, pp. 346353.

Leshed, Gilly; Maria Håkansson; and Joseph Jofish Kaye (2014). Our life is the farm and farming is our life: Home-work coordination in organic farm families. In S. Fussell; W. Lutters; M. R. Morris; 
and M. Reddy (eds): CSCW '14. Proceedings of the 17th ACM conference on Computer supported cooperative work and social computing, Baltimore, MD, USA, 15-19 February 2014. New York: ACM Press, pp. 487-498.

Liegl, Michael (2014). Nomadicity and the Care of Place-on the aesthetic and affective Organization of Space in freelance creative work. Computer Supported Cooperative Work (CSCW), vol. 23, no. 2, April 2014, pp.163-183.

Light, Ann; and Yoko Akama (2014). Structuring future social relations: The politics of care in participatory practice. In V. D'Andrea and O. S. Iversen (eds): PDC '14. Proceedings of the 13th Participatory Design Conference: Research Papers, Windhoek, Namibia, 6-10 October 2014, vol. 1. New York: ACM Press, pp. 151-160.

Light, Ann; and Yoko Akama (2017). The nature of 'obligation', In T. Fisher and L. Gamman (eds): Doing design with communities: Participation, politics and care tricky design: Ethics through things. London: Bloomsbury.

Lingel, Jessa (2017). Digital Countercultures and the Struggle for Community. Cambridge Massachusetts, London England: The MIT Press.

Luff, Paul; and Christian Heath (1998). Mobility in collaboration. In S. Poltrok and J. Grudin (eds): CSCW 1998. In Proceedings of the conference on computer-supported cooperative work, Seattle, USA, 14-18 November 1998. New York: ACM Press, pp. 305-314.

Luff, Paul; Jon Hindmarsh; and Christian Heath (2000). Workplace studies: Recovering work practices and informing design. Cambridge University Press.

Mas, Alexandre; and Amanda Pallais (2016). Valuing alternative work arrangements. American Economy Review, vol. 107, no. 2, pp.1995-2015.

McCarthy John; and Peter Wright (2015). Taking [A]part. The politics and aesthetics of participation in experience-centered design. Cambridge, Massachusetts, London, England: The MIT Press.

McLaren, Duncan; and Julian Agyeman (2015). Sharing Cities. A Case for Truly Smart and Sustainable Cities. Cambridge, Massachusetts, London, England: The MIT Press.

Molz, Jennie G. (2012). CouchSurfing and network hospitality: 'It's not just about the furniture'. Hospitality and Society, vol 1, no. 3, February 2012, pp. 215-225.

Molz, Jennie G. (2014). Toward a network hospitality. First Monday, vol 19, no. 3, March 2014.

Nippert-Eng, Christena (1995). Home and Work. Chicago and London: The University of Chicago Press.

Normark, Maria; and David Randall (2005). Local Expertise at an Emergency Call Centre. In: Gellersen; K. Schmidt; M. Beaudouin-Lafo; and W. Mackay (eds): ECSCW '05. Proceedings of the Ninth European Conference on Computer-Supported Cooperative Work, 18-22 September 2005, Paris, France. Dordrecht: Springer, pp. 347-366.

Parigi, Paolo; and Bogdan State (2014). Disenchanting the world: The impact of technology on relationships. In L. M. Aiello, D. McFarland (eds): Socinfo '14. Proceedings of the International Conference on Social Informatics, Barcelona, Spain, 11-13 November 2014. Springer, pp. 166182.

Perry, Mark; Kenton O'Hara; Abigali Sellen; Barry Brown; and Richard Harper (2001). Dealing with Mobility: Understanding Access Anytime, Anywhere. In ACM Transactions on Computer-Human Interactions (TOCHI), vol. 8, no. 4, pp. 323-347.

Puig de la Bellacasa, Maria (2012). Nothing comes without its world: Thinking with care. The Sociological Review, vol. 60, no 2, pp.197-216.

Ranciére, Jacques (2010). Dissensus. On Politics and Aesthetics. London, New York: Bloomsbury.

Robertson, Toni; and Ina Wagner (2013). Ethics: Engagement, representation and politics-in-action. In Routledge International Handbook of Participatory Design. Routledge, pp. 64-85.

Robertson, Toni; and Jesper Simonsen (2013). Participatory design: An introduction. In Routledge International Handbook of Participatory Design. Routledge, pp. 1-18. 
Rosen, Devan; Pascale R. Lafontaine; and Blake Hendrickson (2011). CouchSurfing: Belonging and trust in a globally cooperative online social network. New Media and Society, vol. 13, no. 6, March 2011, pp.981-998.

Rossitto, Chiara; and Kerstin Severinson Eklundh (2007). Managing work at several places: A case of project work in a nomadic group of students. In D. H. Ham and B. L. William Wong (eds): ECCE '07. Proceedings of the 14th European conference on Cognitive ergonomics: invent! explore! 28 31 August 2007, London, UK. New York: ACM Press, pp. 45-51.

Rossitto, Chiara; Cristian Bogdan; and Kerstin Severinson-Eklundh (2014). Understanding constellations of Technologies in use in a collaborative nomadic setting. Computer Supported Cooperative Work (CSCW), vol. 23, no. 2, April 2014, pp. 137-161.

Rossitto, Chiara; Fabiano Pinatti De Carvalho; Luigina Ciolf; Airi Lampinen; and Breda Gray (2017). Nomadic cultures beyond work practices. International Reports on Socio-Informatics (IRSI), vol. 14 , no. 3, pp. 5-14.

Schmidt, Kjeld (2000). The critical role of workplace studies in CSCW. In P. Luff; J. Hindmarch; and C. Heath (eds): Workplace Studies: Recovering Work Practices and Performing Design. Cambridge: Cambridge University Press.

Schmidt, Kjeld; and Liam Bannon (1992). Taking CSCW seriously. In Computer Supported Cooperative Work (CSCW), vol. 1, no. 2, pp. 7-40.

Schor, Juliet; and Connor Fitzmaurice (2015). Collaborating and connecting: The emergence of the sharing economy. In L. A. Reisch and J. Thøgersen (eds): Handbook of research on sustainable consumption. Edward Elgar Publishing, pp. 410-425.

Star, Susan Leigh; and Karen Ruhleder (1996) Steps toward an ecology of infrastructure: Design and access for large information spaces. Information Systems Research (ISR), vol. 7, no. 1, March 1996, pp. 111-134.

$\mathrm{Su}$, Norman; and Gloria Mark (2008). Designing for nomadic work. In J. van der Schljff and G. Mardsen (eds): DIS '08. Proceedings of the 7th ACM conference on designing interactive systems, cape town, South Africa, 25-27 February 2008. New York: ACM Press, pp. 305-314.

Suchman, Lucy (1995). Making work visible. Communications of the ACM, vol. 38, no. 9, September 1995 , pp. 56-64.

Suchman, Lucy (2007). Human-machine reconfigurations. Plans and situated actions 2ndEdition. Cambridge: Cambridge University Press.

Tan, Jun. E. (2010). The leap of faith from online to offline: An exploratory study of Couchsurfing.org. In A. Acquisti; S. W. Smith; and A-R.Sadeghi (eds.): Trust and trustworthy computing. Heidelberg, Germany: Springer, pp. 367-380.

Verheyen, Gunther (2013). Scrum - A pocket guide: A smart travel companion. Zaltbommel: Van Haren Publishing.

Wailenmann, Alexandra (2003). Doing mobility. PhD. dissertation. Göteborg University, Sweden: Department of Informatics.

Weiss, Robert (1994). Learning from Strangers. The Art and Method of Qualitative Interview Studies. New York: The Free Press. 